\title{
Performance Characteristics of Road-base Containing Mixed Steel Slag and Cathode Ray Tube Glass
}

\author{
Ahmad Yusri Mohamad ${ }^{1, *}$, Maslina Jamil', Nur Izzi Md. Yusoff ${ }^{1}$, Mohd Raihan Taha' \\ ${ }^{1}$ Department of Civil Engineering, Faculty of Engineering \& Built Environment, Universiti Kebangsaan Malaysia, 43600 UKM Bangi, \\ Selangor, Malaysia \\ ${ }^{2}$ Department of Architecture and Built Environment, Faculty of Engineering \& Built Environment, Universiti Kebangsaan Malaysia, \\ 43600 UKM Bangi, Selangor, Malaysia
}

Received November 3, 2020; Revised December 15, 2020; Accepted January 20, 2021

\section{Cite This Paper in the following Citation Styles}

(a): [1] Ahmad Yusri Mohamad, Maslina Jamil, Nur Izzi Md. Yusoff, Mohd Raihan Taha , "Performance Characteristics of Road-base Containing Mixed Steel Slag and Cathode Ray Tube Glass," Civil Engineering and Architecture, Vol. 9, No. 1, pp. 42 - 51, 2021. DOI: 10.13189/cea.2021.090104.

(b): Ahmad Yusri Mohamad, Maslina Jamil, Nur Izzi Md. Yusoff, Mohd Raihan Taha (2021). Performance Characteristics of Road-base Containing Mixed Steel Slag and Cathode Ray Tube Glass. Civil Engineering and Architecture, 9(1), 42 - 51. DOI: 10.13189/cea.2021.090104.

Copyright $\bigcirc 2021$ by authors, all rights reserved. Authors agree that this article remains permanently open access under the terms of the Creative Commons Attribution License 4.0 International License

\begin{abstract}
One way to promote sustainability in construction is through the preservation of natural resources and utilization of recycled wastes. This paper describes a laboratory study on the use of steel slag and cathode ray tube (CRT) glass for road base pavement layer. Measurements of the physical and mechanical characteristics of each sample are taken to evaluate the effectiveness of using these materials in road base pavements. The laboratory evaluation comprised of Los Angeles abrasion value (LAAV) test, California bearing ratio (CBR) test and performance characterization; the unconfined compression strength (UCS) and indirect tensile strength (ITS) tests were also performed. The values for LAAV are satisfactory, indicating that the steel slag and granite mixtures have adequate resistance and abrasion for use as road base pavement aggregates. The higher percentages of steel slag in the mixture produced higher CBR values for both the soaked and unsoaked mixtures. Test results also show that the mixtures containing up to $70 \%$ steel slag and $15 \%$ CRT glass meet the standards requirements. Results of the UCS and ITS tests for performance characterization showed that the performance of the sample mixture was enhanced significantly upon incorporating a higher percentage of steel slag in the mixture. The lab test results showed that the mixture composing of granite, steel slag and CRT glass is a suitable alternative made from recyclable materials, for use in road base pavement layer.
\end{abstract}

Keywords Recycled Materials, Steel Slag, Cathode Ray Tube Glass, Natural Aggregates, Road Base

\section{Introduction}

Sustainable management is defined as effective utilization of resources in order to fulfil human needs whilst ensuring preservation of the environment, not only for the present generation but also for future generations [1]. Preservation of natural resources and utilizations of recycled wastes are among the ways for achieving a sustainable management [2-3]. This will ensure that an effective use of resources can be achieved for future generations. Wastes consist of industrial by-product and commercial wastes, as well as waste debris from demolition and destruction of buildings; these materials are no longer considered to be valuable $[4,5]$. Environmental and economic factors, in addition to the inadequate supply of construction materials faced by some countries have prompted the effort to identify recyclable industrial waste materials that are suitable for construction application [6]. Arulrajah et al. [7] investigated the possibility of producing a new geopolymer construction material from waste materials. Among the materials that could potentially be used as alternative materials in the 
construction industry are recycled glass, spent coffee grounds, fly ash and slag. The use of these wastes has led to the production of green concrete that is environmentally friendly. It also has a positive impact on the coordination of effective waste management and contributes to a sustainable solution for a green future. The various types of by-products and wastes being investigated by researchers throughout the world are steel slag, electronic glass waste, plastic waste, coal fly ash, scrap waste, and others. Several studies have been carried out on reusing by-products and residual wastes as recycled materials. Among them, are the utilization of wastes as additive or substitute in concrete and cement mixtures [8-12]; as soil stabilization in geotechnical soil work; and in various stages of road construction [13-16].

Pasetto and Baldo [13] obtained a satisfactory result when using waste materials consisting of a mixture of steel slag, ladle furnace slag, waste foundry sand, glass waste, and coal ash. The resulting mixture is a cement bound mixture that possessed adequate physical, mechanical and toxicological characteristics to be used in road construction. Sas et al. [14] concluded that steel slag is best used for the construction of roads with medium traffic load. Disfani et al. [15] concluded that recycled glass material can potentially be used in road construction works. Such conclusion is deduced from the result of shear strength tests, which showed that the medium and fine glasses produced similar parameters for shear strength compared to a mixture of gravel and natural sand with angular particles. Kim et al. [16] subjected three different mixing ratios of $50,75 \& 100 \%$ of fly ash content by weight to a variety of tests. The results showed that all mixing ratio of fly ash can be used for constructing highway embankments, provided that the construction follows proper design and construction procedures.

However, research findings by Zhao et al. [11] showed that the application of up to $75 \%$ cathode ray tube (CRT) glass as a replacement for refined aggregates led to a production cost that is $12.38 \%$ higher, per $1 \mathrm{~m}^{3}$ of concrete, than the cost of producing ordinary (control) concrete. Despite this drawback, this method is able to reduce the space required for the disposal of CRT glass and thus contribute positively to environmental management. Kosior-Kazberuk and Grzywa [10] have discovered a method for producing sustainable concrete beam structures which utilize $100 \%$ recycled coarse aggregates. Ismail and Al-Hashmi [12] employed glass residues obtained from glass bottles and window glass with an optimum mix of $20 \%$ replacement to produce concrete with maximum compressive strength and bending, relative to the control concrete. The pozzolanic effect of glass residue can be observed after the concrete sample is cured by immersion for 28 days. Other studies of glass materials and results of laboratory tests have shown that the recycled glass materials used to replace fine and medium aggregates have similar geotechnical properties as natural aggregates [17].

Maghool et al. [26] attempted to determine the concentration of leached heavy metal elements using the Australian Standard Leaching Procedure (ASLP) method. The leaching test was carried out on a sample of steel slag used as a road pavement layer and as a filler material. The results of this test were compared against the Environmental Protection Agency (EPA)'s standard, i.e. the standards set by the Australian authorities. The results of heavy metal element analysis indicated that there is no environmental risk arising from the use of steel slag aggregates. Pauzi et al. [33] studied how using CRT glass substitute for aggregates in cement mixtures affect the environment by conducting a leaching test to determine the concentration of lead $(\mathrm{Pb})$ leached by CRT glass. The results of Toxicity Characteristics Leaching Procedure (TCLP) method showed that concrete specimens containing spherical CRT glass (GS) and crushed CRT glass (GC) with a particle size of between $19 \mathrm{~mm}$ to $4.75 \mathrm{~mm}$ do not release $\mathrm{Pb}$ in acid rain reaction conditions.

At present, many studies are being carried out on using steel slag as aggregates in road construction, either as a substitute for fine or coarse aggregates in the surface layer or in the road base and subbase layers. Some studies have shown the effectiveness of using CRT glass waste due to its good properties when used as aggregate replacement in concrete mixtures. Therefore, a study to identify how by-products materials, i.e. steel slag, and electronic waste, i.e. CRT glass, can potentially be used as alternative materials in road construction. These two materials, when used optimally, could help alleviate demand for natural aggregates. The aim of using alternative materials especially from recyclables will lead to a lower demand for landfill space to dispose these materials, thereby ensuring environmental preservation and achieving a more achieve sustainable development in road construction. This study aims to evaluate the performance of mixture made from recycled materials, namely CRT glass and steel slag. Six different proportions of recycled materials are used as replacement for natural aggregates.

\section{Materials and Methods}

\subsection{Materials}

The specimens used in this study are prepared from three types of aggregates, i.e. granite (natural aggregates), steel slag (by-product material), and CRT glass (electronic waste). Steel slag is a secondary product derived from the production process of stainless steel, through processing in the electric arc furnace (EAF) and basic oxygen furnace (BOF). The residual product is generated from the melting of scrape produces steel that is categorized as EAF while those generated in the conversion iron to steel are categorized as BOF [6]. 


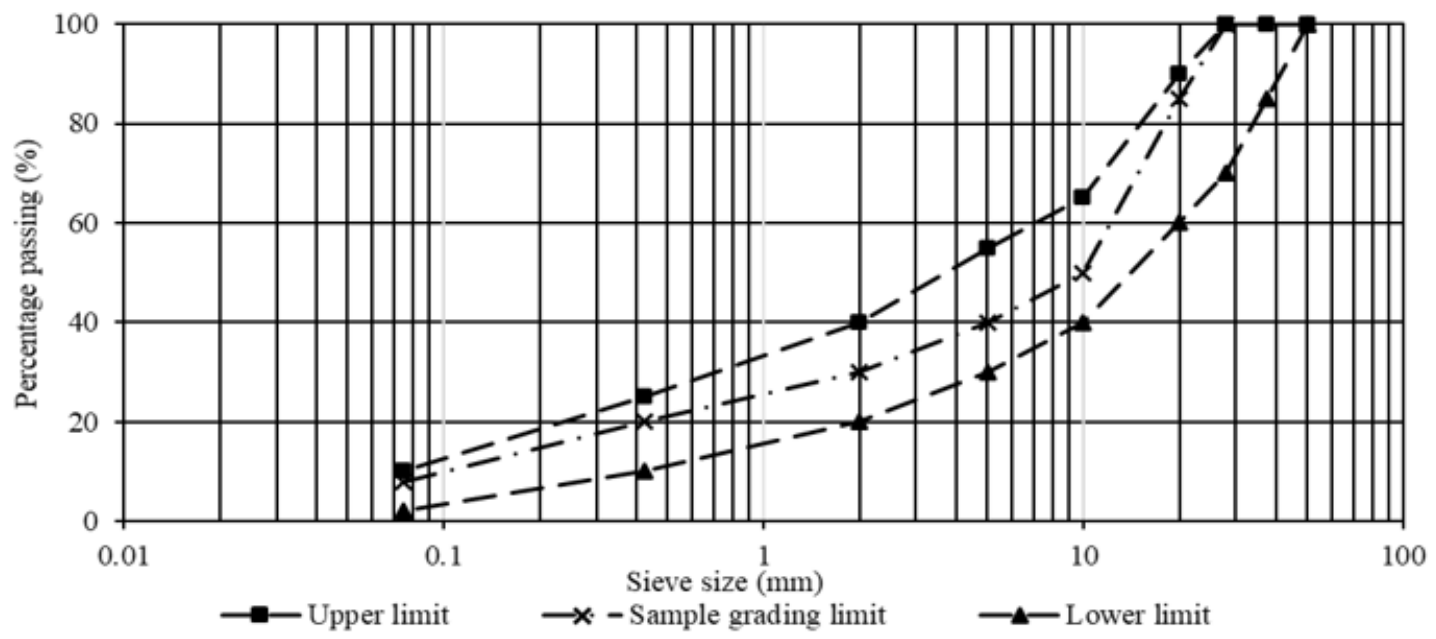

Figure 1. Particle size distribution of the sample

The CRT glass was prepared by subjecting it through a few processes. First, the CRT glass components were separated by cutting them with laser. They were then crushed into smaller fragments of $5 \mathrm{~mm}$ maximum size. Next, the CRT glass went through a crushing process to obtain the angular particles and the grading process was done to obtain the desired size.

To establish the appropriate aggregate size to be used in the mixture for pavement road base layer, a sieve analysis was conducted. A few samples were obtained from sieving the aggregates according to the sizes specified in the British Standard (BS). Figure 1 is the gradient curve for a mixture in the proposed reference envelope. To ensure a good and effective interlocking of the particles, the sample must be graded to make certain that the final sample complies with the standards used. Furthermore, to a good sample that has been consistently graded, the selected samples have an average value that is within both the permissible limits to ensure that the test has been performed accurately and in accordance with the specifications.

Table 1. Percentage of combination mixture proportions

\begin{tabular}{|c|c|c|c|c|c|}
\hline \multirow{3}{*}{$\begin{array}{c}\text { Samp } \\
\text { le }\end{array}$} & \multicolumn{5}{|c|}{ Percentage aggregate (\%) } \\
\hline & \multicolumn{2}{|c|}{ Coarse aggregate } & \multicolumn{3}{|c|}{ Fine aggregate } \\
\hline & Granite & $\begin{array}{l}\text { Steel } \\
\text { slag }\end{array}$ & Granite & $\begin{array}{l}\text { Steel } \\
\text { slag }\end{array}$ & $\begin{array}{l}\text { CRT } \\
\text { Glass }\end{array}$ \\
\hline A1 & 100 & - & 100 & - & - \\
\hline A2 & 70 & 30 & 85 & - & 15 \\
\hline A3 & 60 & 40 & 85 & - & 15 \\
\hline A4 & 50 & 50 & 85 & - & 15 \\
\hline A5 & 30 & 70 & 85 & - & 15 \\
\hline A6 & - & 100 & - & 85 & 15 \\
\hline
\end{tabular}

The percentage of mixtures used in this study is shown in Table 1 . The different proportion of the aggregates in the mixes enabled the identification of its impact on the material properties. The granite used in mixtures A1 to A5 had a maximum nominal size of $20 \mathrm{~mm}$. For mixture A1, $100 \%$ granite was used as the coarse aggregates and fine aggregates. The A1 mixture is designated as the control mixture. For the fine aggregate mix, the natural aggregates were replaced with CRT glass specimens, where only $15 \%$ of the granite was replaced with CRT glass. Meanwhile, the coarse aggregate mix for the A6 mixture is made up of $100 \%$ steel slag, while the fine aggregate mix consists of $85 \%$ steel slag and 15\% CRT glass.

\subsection{Physical and Mechanical Tests}

Each sample was subjected to physical and mechanical tests to evaluate the effectiveness of the materials. Three replicate samples went through the tests, and the average of the three values was recorded. The three physical tests conducted were specific gravity, water absorption, and flakiness index. The first two tests were carried out in accordance with ASTM C127 and ASTM C128, respectively. The flakiness index test was performed following BS 812: section 105.1: 1990 to determine the percentage of flattened aggregates. The mechanical tests conducted in this study are the aggregate impact value (AIV) test, aggregate crushing value (ACV) test, and soundness test. Each of these tests was also run according to the relevant standards, i.e. BS 812: Part 112: 1990; BS 812: Part 110: 1990; and ASTM C88 for AIV, ACV and soundness tests, respectively.

\subsection{Los Angeles Abrasion Value (LAAV) Test}

The resistance and abrasion properties of the structures constructed using industrial wastes must be established. The properties of granite and steel mixtures as a base material for road pavements were determined using the LAAV test. In accordance with ASTM C131-81, the LAAV test aimed at evaluating the abrasion, shifting and 
cracking properties as well as any combination of the three characteristics. Samples with different sizes of coarse aggregates in the amount of $5 \mathrm{~kg}$ were placed in a steel drum together with a specific number of steel balls, where the drum was then rotated at a speed of $33 \mathrm{rpm}$ for up to 500 times. The aggregates were removed from the machine and sifted through a sieve of $1.70 \mathrm{~mm}$. The sample used for this test is a mixture of granite and steel slag. For this test, two sample grades were used, where grade $\mathrm{B}$ is aggregates that passed the $19.0 \mathrm{~mm}$ sieve, but retained on the $9.5 \mathrm{~mm}$ sieve, while grade $\mathrm{C}$ is the aggregates that passed the $9.5 \mathrm{~mm}$ sieve but retained on the $4.75 \mathrm{~mm}$ sieve.

\subsection{California Bearing Ratio (CBR) Test}

The CBR test was run on the samples compacted using modified proctor compaction at an optimum moisture content (OMC) to obtain a maximum dry density (MDD) of 95\%, in accordance with BS 1377: Part 4. The sample was placed in a cylinder mould measuring $152 \mathrm{~mm}$ in diameter, $127 \mathrm{~mm}$ in depth, and a minimum of $5 \mathrm{~mm}$ in wall thickness. The mould was fitted with a collar and base plate connections. The samples were placed in the mould in five layers, each of which is uniformly compacted by 62 blows of a $4.5 \mathrm{~kg}$ rammer that falls freely from a height of $450 \mathrm{~mm}$. Both the soaked sample and unsoaked sample underwent the same CBR test. For the soaked sample, it was left to soak for 4 days, with a $4.5 \mathrm{~kg}$ surcharge mass applied on top, followed by a penetration test performed at a rate of $1 \mathrm{~mm} / \mathrm{min}$.

At the penetration test, the dial gauge reading was recorded at every $0.25 \mathrm{~mm}$ increment up to a final increment of $7.5 \mathrm{~mm}$. A force against penetration curve was plotted, using the standard force values i.e. $13.2 \mathrm{kN}$ at $2.5 \mathrm{~mm}$ penetration and $19.8 \mathrm{kN}$ at $5.0 \mathrm{~mm}$ penetration. The higher of the two values was taken as the final result.

\subsection{Performance Characterization of the Mixture}

\subsubsection{Unconfined compression strength (UCS) test}

UCS is an important parameter in the estimation of the stiffness of pavement material and is used in the design of mechanical pavements. The mixed samples were compacted using a modified compaction method. As with $\mathrm{CBR}$, the samples were placed in 5 layers. Each layer was compacted by 25 blows of a $4.5 \mathrm{~kg}$ hammer. A hydraulic compression strength test machine was used to apply a constant compression rate of $140 \mathrm{kPa} / \mathrm{s}$ during the compression strength test, in line with ASTM D1633. The UCS mixture samples were prepared in a metal cylinder mould, measuring $101.60 \mathrm{~mm}$ in internal diameter and $116.4 \mathrm{~mm}$ in depth. The samples were a blend of aggregate mixtures stabilized with $4 \%$ cement (by weight). The samples were cured by placing them in the moulds, kept for 12 hours in a moist room, and then removed with a sample extruder. The samples that were removed had plastic wrappings to prevent contact with any water drippings in the moist room, which has a temperature of 25 0C. The samples were then cured in water for 7 days, in line with the minimum requirement for UCS test. The highest UCS value is identified for use as a design mix. The UCS value is defined as the maximum load divided with the cross-sectional area. The base mixture for the indirect tensile strength (ITS) test was prepared in the similar way to the UCS test to ensure the achievement of a significant value for other performance strength characteristics [18].

\subsubsection{Indirect tensile strength (ITS) test}

The ITS test is a destructive test used to determine a sample mix's crack resistance. The preparation and compaction of samples for the ITS test are similar to those for UCS. In line with ASTM D1632, the sample mixture was put together in a cylindrical metal specimen mould measuring $101.60 \mathrm{~mm}$ in internal diameter and $63.5 \mathrm{~mm}$ in depth. Meanwhile, the ITS test procedure, followed ASTM D6931, used the universal testing machine (UTM) to impose a compression load at a rate of $50 \pm 5 \mathrm{~mm} / \mathrm{min}$ on the samples. The cylindrical samples were placed between two load strips, then loaded for a relatively uniform tensile stress with a compressive load along a diametrical plane and perpendicular to the applied load plane. The procedure went on until the maximum load is reached and the specimen failed. This maximum load at failure value of the sample, $\mathrm{P}$, was recorded in $\mathrm{N}$. The formula to calculate the indirect tensile strength is defined in equation (1), where $t$ is the specimen height in $\mathrm{mm}$ measured immediately before the test, while $\mathrm{D}$ is the specimen diameter in $\mathrm{mm}$.

$$
\operatorname{ITS}(\mathrm{kPa})=2000 \mathrm{P} / \pi \mathrm{tD}
$$

\subsection{Statistical Analysis}

This study also used statistical analysis to compare the statistical models which have been developed for a data; this is done to ascertain that the model is the most appropriate fit for the properties of the result.

A common method to compare the means between two or more test groups is the one-way analysis of variance, or ANOVA, in which two different estimates for data variance are taken. One estimate is the between-group variance, which measures the effect of the variable combined with error. The other one, the within-group variance, is the variance of the error. The $p$ value is the significance of the parameter $\mathrm{F}$, where $\mathrm{F}$ is the ratio of between-group variance to within-group variance, tested at 0.05 significance level. A p value less than this 0.05 indicates that there is a significant difference in the obtained mean value. 


\section{Result and Discussion}

\subsection{Physical and Mechanical Properties}

Table 2 presents the physical and mechanical properties of the aggregates used in this study - granite, steel slag and CRT glass. As can be seen, steel slag specific gravity, which measures an aggregate's strength, is $32 \%$ more than granite. Aggregate samples with high specific gravity values are usually stronger [19][20]. The water absorption value for steel slag is higher than those for granite and CRT glass. This implied that steel slag is of higher porosity, meaning that it has the ability to absorb more water than the remaining two aggregates, i.e. CRT glass and granite. However, the water absorption value of steel slag still meets the specification requirement. Romero et al. [20] pointed out that a higher water absorption by the aggregates indicates a high porosity of the aggregate sample. Granite has a higher flakiness index than steel slag. Based on the findings of previous studies, flaky aggregates are typically not suitable for pavement construction due to compaction difficulty and low workability. Oluwasola et al. [6] have shown that steel slag has a low flakiness index, and this is associated with the rounded physical shape of steel slag. To improve interlocking properties, a combination of steel slag with other materials, for instance granite, is recommended. Road capacity must be taken into account in terms of the ability of aggregates to resist crushing caused by vehicle load on the road. The stability of road pavement structure can be affected if weak aggregates are used. The ACV and AIV show that the granite and steel slag samples used in the present study meet the standard requirements. Adebola and Abdulazeez [21] have shown that low crushing value and aggregate impact value produced high quality road pavements. The result for soundness test showed that steel slag has a higher durability and stability in contrast to granite, where the soundness value for steel slag is $90 \%$ lower than the value for granite. In general, the result for the steel slag aggregates presented in Table 4 is comparable with the typical values and meet the ASTM C88 specifications. This indicates that the sample is highly durable and has the ability to resist bad weather conditions, in particular freezing and thawing. The result has proven that steel slag possesses positive, stable and suitable material properties as well as a good soundness value.

\subsection{LAAV Test}

The LAAV values for both test conditions are shown in Figure 2. The LAAV of the grade $\mathrm{C}$ mixture has a better abrasion resistance than grade B. The A5 mixture has a better value for both tests. The values for the grade $\mathrm{B}$ and grade C are $24.93 \%$ and $22.12 \%$, respectively. Steel slag's smaller value indicates that it has good mechanical properties and wear resistance. The LAAV of both mixture grades decreased with higher amounts of steel slag relative to the natural aggregate. The presence of steel slag in all mixtures gives the mixtures their high abrasion strength and wear resistance. Steel slag is a dark-coloured material with a high hardness, density and abrasion resistance [24-25], where the high density and hardness of steel slag are due to the presence free iron in steel slag. These properties and characteristics of steel slag showed that it is an appropriate and beneficial substitute for the aggregates to be used in road construction works [14, 22-23]. Overall, the LAAV value of each mixture meets the maximum allowable value by ASTM C131-81, which is less than $45 \%$. Therefore, the combination of steel slag with natural aggregates (granite) can produce an aggregate mixture with adequate strength.

Table 2. Physical and mechanical properties requirement

\begin{tabular}{|c|c|c|c|c|c|}
\hline \multirow{2}{*}{ Test } & \multirow{2}{*}{ Test Method } & \multicolumn{3}{|c|}{ Sample aggregate } & \multirow{2}{*}{$\begin{array}{l}\text { Specification } \\
\text { Requirements }\end{array}$} \\
\hline & & Granite & Steel slag & CRT glass & \\
\hline \multicolumn{6}{|c|}{ Physical properties } \\
\hline Specific gravity & ASTM C127 & 2.68 & 3.55 & 2.54 & - \\
\hline Water absorption & ASTM C128 & 0.49 & 1.80 & 0.19 & $<2 \%$ \\
\hline Flakiness index & $\begin{array}{l}\text { BS 812: part } \\
\text { 105.1:1990 }\end{array}$ & 8.00 & 5.60 & - & $<25 \%$ \\
\hline \multicolumn{6}{|c|}{ Mechanical properties } \\
\hline $\begin{array}{l}\text { Aggregate crushing } \\
\text { value }\end{array}$ & $\begin{array}{l}\text { BS 812: part } \\
\text { 110:1990 }\end{array}$ & 20.10 & 25.60 & - & $<30 \%$ \\
\hline Aggregate impact value & $\begin{array}{l}\text { BS 812: part } \\
\text { 112:1990 }\end{array}$ & 15.10 & 17.80 & - & $<30 \%$ \\
\hline Soundness & ASTM C88 & 0.20 & 0.02 & 0.41 & $<18 \%$ \\
\hline
\end{tabular}




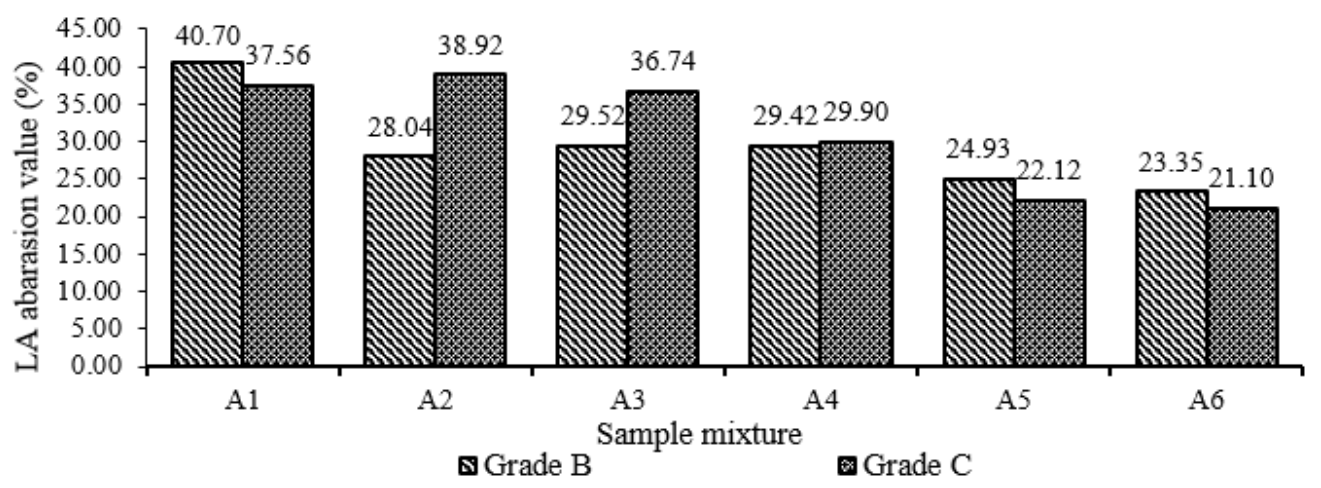

Figure 2. LA abrasion values (\%) of the sample mixture

\subsection{CBR Test}

Table 3 shows CBR values of the sample mixtures, both soaked and unsoaked. The highest CBR value of soaked and unsoaked A5 mixture was obtained for the same mixing condition. The CBR values for soaked and unsoaked A5 mixture are $316.66 \%$ and $272.72 \%$, respectively. Mixture A4 has CBR values of $239.87 \%$ and 200.98\%; while the values for A3 are $211.79 \%$ and $196.46 \%$, those for A2 are $191.74 \%$ and $168.03 \%$, and the control mixture, A1, has CBR values of $146.01 \%$ and $117.62 \%$, respectively, for the soaked and unsoaked condition. In addition, all samples have a much higher CBR value than the control mixture, A1, and meet the minimum required value of $80 \%$. This result indicates that the increasingly higher percentages of steel slag in mixtures A2 to A5 resulted in correspondingly higher CBR values of each mixture. Maghool et al. [26] and Singh et al. [27] found that the suitability of a material used in road construction was influenced by the material's CBR value. However, using $100 \%$ steel slag as coarse aggregates in mixture A6 has significantly reduced the CBR value, with values of soaked and unsoaked A6 mixtures of $254.62 \%$ and $216.49 \%$, respectively. The lower CBR value of the A6 mixture can be caused by poor adhesion between steel slag particles due to its increased porosity, which in consequence affects the crack around the steel slag particles. Nevertheless, it still had a higher CBR value than the control mixture (A1) and met BS 1377 specifications. Behiry [24] and Li et al. [28] stated that the higher porosity of the mixed sample is one of the factors contributing to the weaker adhesion of the aggregates. The test results also showed that mixtures with higher steel slag content have higher MDD and lower OMC. The permeability and shear resistance are higher when the aggregates are in a dry side compared to when the aggregates are in the wet side [29]. This contributes to a better interlocking between aggregates.

The rough, uneven, irregular surface of the granite and steel slag used as coarse aggregates contribute to strengthen the bond between the granite and steel slag. Maghool et al. [26] stated that the increase in CBR value is also influenced by the compaction method, which in turn strengthen the bond between the compacted particles. Meanwhile, the findings by Ismail and Al-Hashmi [12] indicated that the use of waste glass as a partial replacement for sand increased the strength of the concrete mix due to the pozzolanic properties of waste glass.

Table 3. CBR values of the soaked and unsoaked sample mixtures

\begin{tabular}{ccccc}
\hline \multirow{2}{*}{$\begin{array}{c}\text { Mixtu } \\
\text { re }\end{array}$} & \multirow{2}{*}{$\begin{array}{c}\text { OMC } \\
(\%)\end{array}$} & \multirow{2}{*}{$\begin{array}{c}\text { MDD } \\
\left(\mathrm{Mg} / \mathrm{m}^{3}\right)\end{array}$} & soaked & unsoaked \\
\hline A1 & 6.40 & 2.120 & 146.01 & 117.62 \\
$\mathrm{~A} 2$ & 6.20 & 2.270 & 191.74 & 168.03 \\
$\mathrm{~A} 3$ & 6.10 & 2.330 & 211.79 & 196.46 \\
$\mathrm{~A} 4$ & 5.90 & 2.390 & 239.87 & 200.98 \\
$\mathrm{~A} 5$ & 5.80 & 2.532 & 316.66 & 272.72 \\
$\mathrm{~A} 6$ & 5.60 & 2.900 & 254.62 & 216.49 \\
\hline
\end{tabular}

\subsection{Performance Characterization}

Figures 3 and 4 show the mix design and the performance results for UCS and ITS respectively. For all samples, the values of UCS and ITS tests increase with higher steel slag content. These results have shown that after 7 days of aging, mixture A6 has an optimum compression strength of 5.67 MPa and an optimum ITS value of $0.60 \mathrm{MPa}$. The compression strength of the A5, A4, A3, and A2 mixtures are 4.85 MPa, 4.35 MPa, 4.23 $\mathrm{MPa}$ and $3.85 \mathrm{MPa}$, respectively, which are all higher than the value of the control mixture (A1), that is $3.64 \mathrm{MPa}$. The ITS test results showed that mixture 6 has the highest tensile strength value of $0.60 \mathrm{MPa}$, followed by A5 (0.51 MPa), A4 (0.46 MPa), A3 (0.44 MPa), A2 (0.42 MPa) and A1 ( $0.40 \mathrm{MPa})$. It is also worth noting that the UCS and ITS values for all samples exceeded the minimum values required by the Malaysian specification [30], i.e. $0.7 \mathrm{MPa}$ (UCS) and 0.2 MPa (ITS).

Using higher amounts of steel slag affects internal strength resistance. The strong bond between the mixture aggregates is due to the uniform distribution of the matrix mixture which provides a strong aggregate coating. The higher internal strength resistance, in turn, improves cracking resistance [31]. 


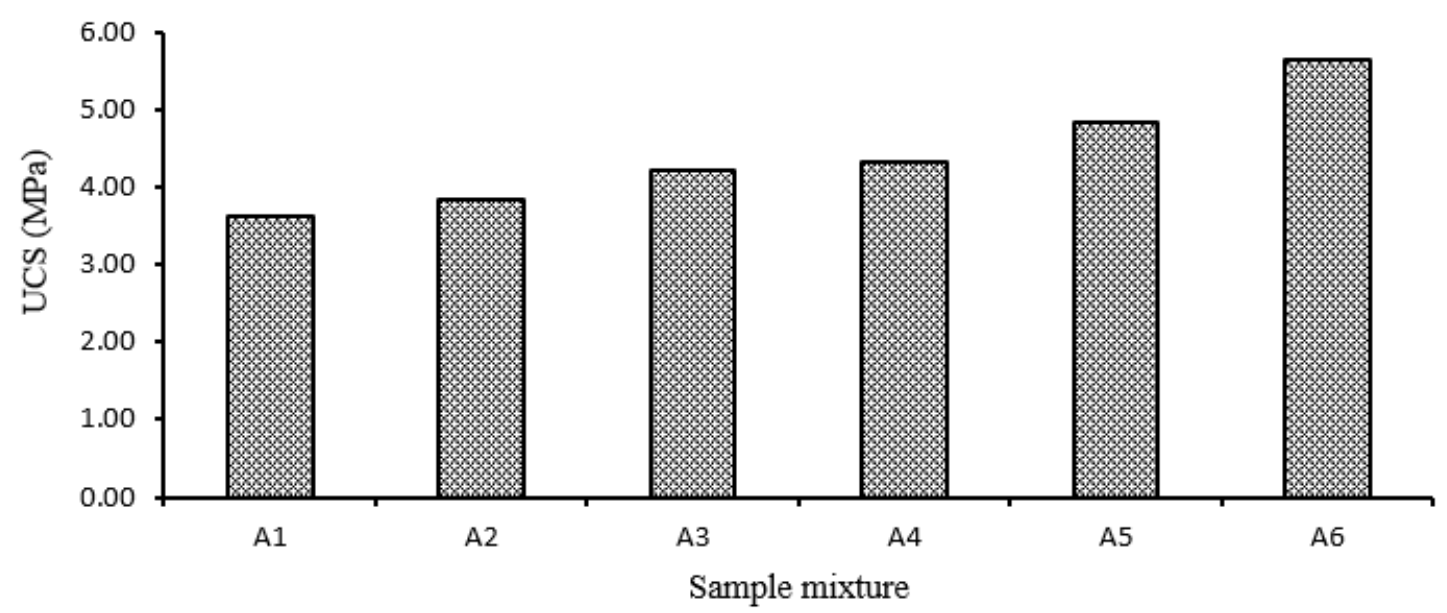

Figure 3. UCS values of the sample mixture

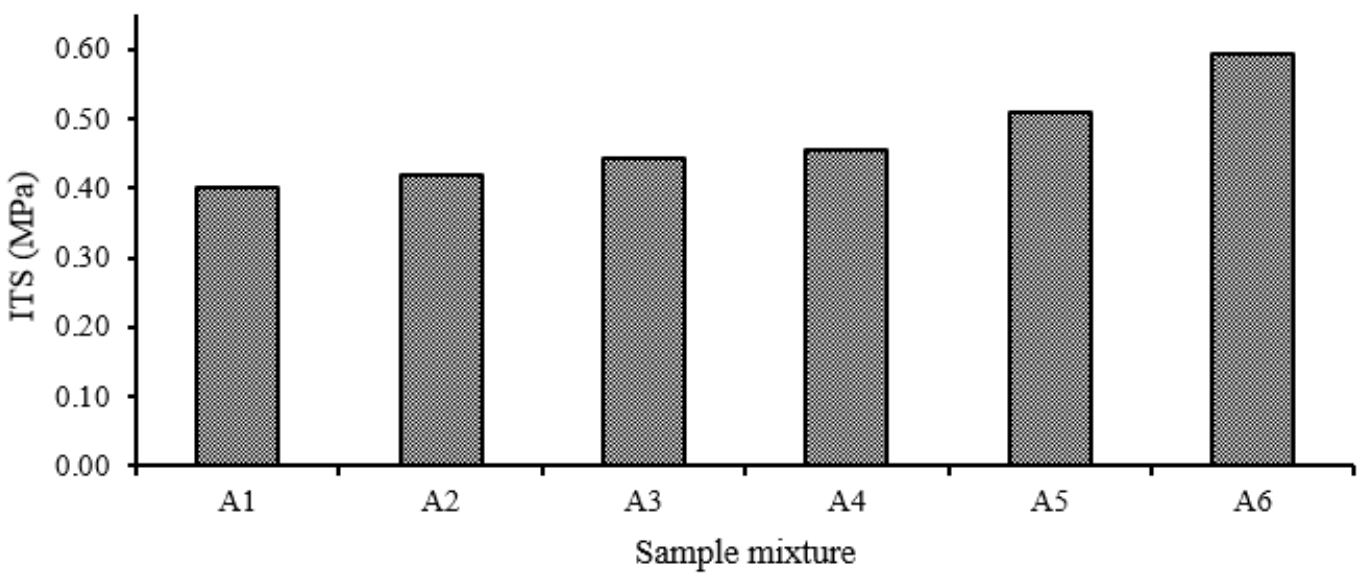

Figure 4. ITS values of the sample mixture

Table 4 shows the standard deviation for the performance characterization (UCS and ITS test) of the different mixtures. The standard deviations are within in the allowable average limit and thus reflect the repeatability of the results of performance characterization of each mixture, where the coefficient of variation confirms the limitation of errors. Table 5 shows the ANOVA, which evaluated the reproducibility of the performance characterization after 7 days of aging. This study compares the performance characterization of different mixtures. The hypothesis was tested using a 0.05 level of significance (p), and result showed that there is no statistically significant difference in the mean values of UCS and ITS for performance characterization. Based on the results in Table 5, the null hypothesis for the assumption of homogeneity of variance was rejected as the (p) value is less than 0.05 , which indicates that there is statistically significant difference across the performance characterization as can be seen based on the results of one-way ANOVA for all tests $(\mathrm{F}(5,12)=170.18$ and 74.706 and $(p)=0.00$ for the UCS and ITS tests). These values indicate that the different mixture samples have significantly different strength properties.

In addition, the linear equation models were used to perform a regression analysis of the experimental values of UCS and ITS. The equation obtained is given by Equation. 2.

$$
\text { ITS }=0.0358 \mathrm{UCS}+0.3459
$$

Figure 5 shows the average experimental data for the regression curve of UCS vs ITS for the different mixtures, where the coefficient of determination, R2, is 0.8822 . The UCS-ITS ratio for all samples range between 9 and 10, as shown in Table 6. It implies a consistent linear relationship between UCS and ITS. The outcome of a study conducted by Pasetto and Baldo [13] and Xuan et al. [32] showed that the ratio of UCS to ITS ranged from 9 to 10 when cement was added into the mix. 
Table 4. Mean and standard deviations of UCS and ITS

\begin{tabular}{ccccccc}
\hline \multirow{2}{*}{ Mixture } & UCS & \multicolumn{3}{c}{ ITS } & & \\
\cline { 2 - 7 } & Mean & $\begin{array}{c}\text { Standard } \\
\text { Deviation }\end{array}$ & $\begin{array}{c}\text { Coefficient of } \\
\text { variation }\end{array}$ & Mean & $\begin{array}{c}\text { Standard } \\
\text { Deviation }\end{array}$ & $\begin{array}{c}\text { Coefficient of } \\
\text { variation }\end{array}$ \\
\hline A1 & 3.642 & 0.141 & 3.861 & 0.402 & 0.008 & 2.070 \\
A2 & 3.848 & 0.089 & 2.317 & 0.419 & 0.014 & 3.414 \\
A3 & 4.136 & 0.087 & 2.099 & 0.443 & 0.017 & 3.916 \\
A4 & 4.226 & 0.062 & 1.465 & 0.456 & 0.016 & 3.467 \\
A5 & 4.851 & 0.100 & 2.051 & 0.510 & 0.014 & 2.830 \\
A6 & 5.665 & 0.100 & 1.756 & 0.595 & 0.014 & 2.354 \\
\hline
\end{tabular}

Table 5. ANOVA for the result of performance characterization

\begin{tabular}{|c|c|c|c|c|c|c|}
\hline $\begin{array}{c}\text { Performance } \\
\text { characterization }\end{array}$ & & Sum of Squares & Df & Mean Square & $\mathrm{F}$ & Sig. \\
\hline \multirow[t]{3}{*}{ UCS } & Between Groups & 8.350 & 5 & 1.670 & 170.118 & 0.00 \\
\hline & Within Groups & 0.118 & 12 & 0.010 & & \\
\hline & Total & 8.468 & 17 & 0.498 & & \\
\hline \multirow[t]{3}{*}{ ITS } & Between Groups & 0.077 & 5 & 0.015 & 74.706 & 0.00 \\
\hline & Within Groups & 0.002 & 12 & 0.000 & & \\
\hline & Total & 0.079 & 17 & 0.005 & & \\
\hline
\end{tabular}

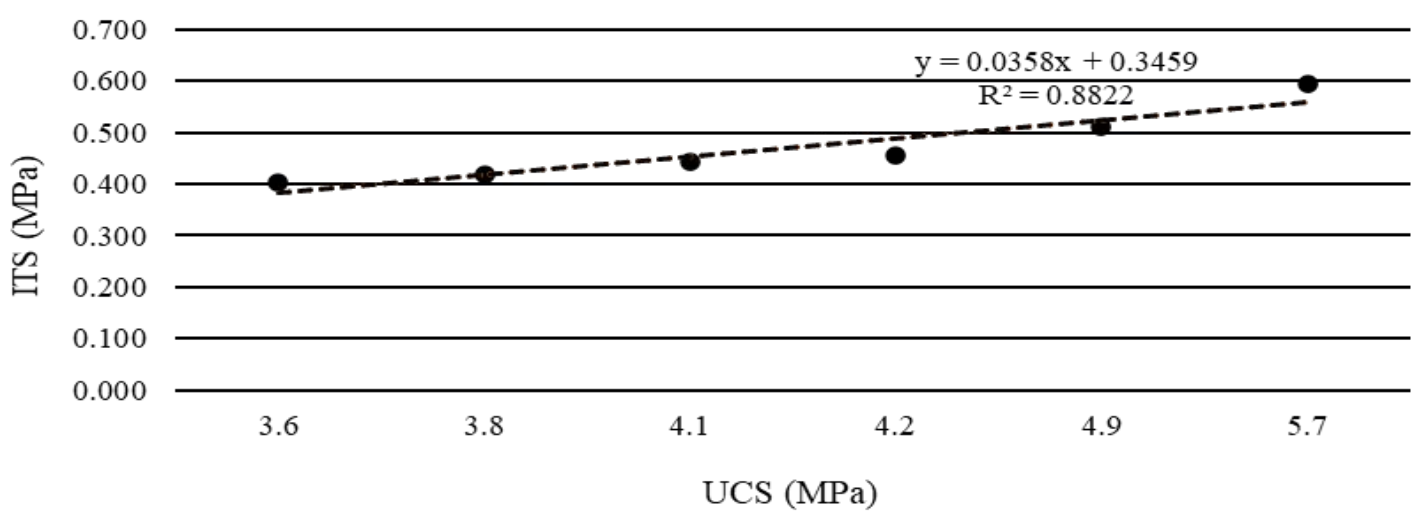

Figure 5. Regression graph for ITS vs UCS

Table 6. Ratio of UCS-ITS

\begin{tabular}{cccc}
\hline Mixture & UCS (MPa) & ITS (MPa) & Ratio UCS-ITS \\
\hline A1 & 3.642 & 0.402 & 9.053 \\
A2 & 3.848 & 0.419 & 9.191 \\
A3 & 4.227 & 0.443 & 9.336 \\
A4 & 4.348 & 0.456 & 9.262 \\
A5 & 4.851 & 0.510 & 9.488 \\
A6 & 5.665 & 0.595 & 9.516 \\
\hline
\end{tabular}

\section{Conclusions}

The aim of this study is to evaluate the performance characteristics of mixtures that contain aggregates of steel slag, CRT glass and granite. The findings have shown that the mixture can be used as a material in road layer construction. From an engineering fill material perspective, the samples, where steel slag and CRT glass are combined with natural aggregate i.e. granite in a mixture, contain physical and mechanical properties that are suitable to be used as materials in road base pavement. The measurement of each test sample showed that CRT glass and steel slag both meet the requirements to be used as aggregates.

The LAAV values of all mixtures decreased when higher percentages of steel slag are incorporated as a replacement for granite. Mixture A5 carries a better LAAV value compared to the other mixtures. Result of the LAAV test shows that all mixtures have values less than the maximum allowable LAAV value of less than $45 \%$. This indicates that the steel slag and granite mixture have adequate resistance and abrasion for use as road base pavement aggregates. The values for CBR indicate that all mixes meet the minimum $80 \%$ requirement of BS 1377 : Part 4 standards. Replacing granite with up to $70 \%$ steel 
slag resulted in higher MDD and CBR values. The CBR values for both soaked or unsoaked mixture samples increased between $2 \%$ to $50 \%$. However, the substitution of $100 \%$ steel slag for the coarse aggregates in the A6 mixtures resulted in a significant reduction in the CBR value, although still within the permissible range.

In terms of performance characterization, the UCS and ITS values for the samples that have been soaked for 7 days fulfilled the minimum requirement (0.7 MPa and 0.2 $\mathrm{MPa}$, respectively). The samples showed a significant strength improvement of between $2 \%$ to $17 \%$. The addition of higher amount of steel slag resulted in higher resistance to internal strength. This in consequence produced a strong bond between the mixed aggregates due to the uniform distribution of the matrix mix, which resulted in enhanced aggregate interlocking. In addition, there is a significant relationship between the values for UCS and ITS for all mixtures. The use of recycled materials, namely CRT glass and steel slag, in roadworks applications, preserves natural resources and is an effective approach for achieving sustainable management.

\section{Acknowledgements}

The authors are grateful for the financial support granted by Universiti Kebangsaan Malaysia (UKM) through its research grant scheme FRGS/1/2017/TK06/UKM/02/2, without which this research would not have been possible.

\section{REFERENCES}

[1] R. Cooke, Building in the 21st Century, Blackwell Publishing, 2007.

[2] P.O. Awoyera, A. Adesina, Plastic wastes to construction products: Status, limitations and future perspective, Case Stud. Constr. Mater. 12, 2020.

[3] A.Y. Mohamad, N.I. Yusoff, M. Raihan, M. Jamil, Physical Properties of Cathode Ray Tube (CRT) Used as Aggregate for Road Pavement Application, J. Kejuruter. 3, 1-5, 2020.

[4] A.M.H. Mansour, S.A. Ali, Reusing waste plastic bottles as an alternative sustainable building material, Energy Sustain. Dev. 24, 79-8, 5, 2015.

[5] A. Arulrajah, M.M. Disfani, S. Horpibulsuk, C. Suksiripattanapong, N. Prongmanee, Physical properties and shear strength responses of recycled construction and demolition materials in unbound pavement base/subbase applications, Constr. Build. Mater. 58, 245-257, 2014.

[6] E.A. Oluwasola, M.R. Hainin, M.M.A. Aziz, Characteristics and utilization of steel slag in road construction, J. Teknol. 70, 117-123, 2014.

[7] A. Arulrajah, T.A. Kua, S. Horpibulsuk, M. Mirzababaei, A.
Chinkulkijniwat, Recycled glass as a supplementary filler material in spent coffee grounds geopolymers, Constr. Build. Mater. 151, 18-27, 2017.

[8] L.G.G. de Godoy, A.B. Rohden, M.R. Garcez, S. Da Dalt, L. Bonan Gomes, Production of supplementary cementitious material as a sustainable management strategy for water treatment sludge waste, Case Stud. Constr. Mater. 12, 2020.

[9] A. Gayan, D. Das, An Effort in Developing a Sustainable Concrete using Marble Powder as Partial Cement Replacement and Quarry Rock Dust as Fine Aggregrate with an Emphasis on Cost of Production, Civ. Eng. Environ. Technol. 3, 293-296, 2016.

[10] M. Kosior-Kazberuk, M. Grzywa, Recycled Aggregate Concrete as Material for Reinforced Concrete Structures, J. Sustain. Archit. Civ. Eng. 7, 60-66, 2014.

[11] H. Zhao, C.S. Poon, T.C. Ling, Utilizing recycled cathode ray tube funnel glass sand as river sand replacement in the high-density concrete, J. Clean. Prod. 51, 184-190, 2013.

[12] Z.Z. Ismail, E.A. AL-Hashmi, Recycling of waste glass as a partial replacement for fine aggregate in concrete, Waste Manag. 29, 655-659, 2009.

[13] M. Pasetto, N. Baldo, Recycling of waste aggregate in cement bound mixtures for road pavement bases and sub-bases, Constr. Build. Mater. 108, 112-118, 2016.

[14] W. Sas, A. Głuchowski, M. Radziemska, J. Dziecioł, A. Szymański, Environmental and geotechnical assessment of the steel slags as a material for road structure, Materials (Basel). 8, 4857-4875, 2015.

[15] M.M. Disfani, A. Arulrajah, M.W. Bo, R. Hankour, Recycled crushed glass in road work applications, Waste Manag. 31, 2341-2351, 2011.

[16] B. Kim, M. Prezzi, R. Salgado, Geotechnical Properties of Fly and Bottom Ash Mixtures for Use in Highway Embankments, J. Geotech. Geoenvironmental Eng. 131, 914-924, 2005.

[17] M.M.. b Disfani, A.. b Arulrajah, M.M.. b Younus Ali, M.W.. Bo, Fine recycled glass: A sustainable alternative to natural aggregates, Int. J. Geotech. Eng. 5, 255-266, 2011.

[18] M. Pasetto, N. Baldo, Experimental analysis of hydraulically bound mixtures made with waste foundry sand and steel slag, Mater. Struct. Constr. 48, 2489-2503, 2015.

[19] F. Maghool, A. Arulrajah, S. Horpibulsuk, Y.-J. Du, Laboratory Evaluation of Ladle Furnace Slag in Unbound Pavement-Base/Subbase Applications, J. Mater. Civ. Eng. 1-9, 2016.

[20] D. Romero, J. James, R. Mora, C.D. Hays, Study on the mechanical and environmental properties of concrete containing cathode ray tube glass aggregate, Waste Manag. 33, 1659-1666, 2013.

[21] M. Adebola, S. Abdulazeez, The Suitability of Some Selected Granite Deposits for Aggregate Stone Production in Road Construction, Int. J. Eng. Sci. Fed. Univ. Technol. Niger. 3, 75-81, 2014.

[22] M.R. Hainin, M.M. A. Aziz, Z. Ali, R. Putra Jaya, M.M. El-Sergany, H. Yaacob, Steel Slag as A Road Construction Material, J. Teknol. 73, 33-38, 2015. 
[23] M.M.E. Zumrawi, F.O.A. Khalill, Experimental Study of Steel Slag Used as Aggregate in Asphalt Mixture, Am. J. Constr. Build. Mater. 2(1), 26-32, 2017.

[24] A.E.A.E.M. Behiry, Evaluation of steel slag and crushed limestone mixtures as subbase material in flexible pavement, Ain Shams Eng. J. 4, 43-53, 2013.

[25] Y.K. Sabapathy, V.B. Balasubramanian, N. Shiva Shankari, A. Yeshwant Kumar, D. Ravichandar, Experimental investigation of surface modified EOF steel slag as coarse aggregate in concrete, J. King Saud Univ. - Eng. Sci. 29, 388-393, 2017.

[26] F. Maghool, A. Arulrajah, Y.J. Du, S. Horpibulsuk, A. Chinkulkijniwat, Environmental impacts of utilizing waste steel slag aggregates as recycled road construction materials, Clean Technol. Environ. Policy. 19, 949-958, 2017.

[27] S.P. Singh, D.P. Tripathy, P.G. Ranjith, Performance evaluation of cement stabilized fly ash - GBFS mixes as a highway construction material, Waste Manag. 28, 13311337, 2008.
[28] J. Li, M. Saberian, B.T. Nguyen, Effect of crumb rubber on the mechanical properties of crushed recycled pavement materials, J. Environ. Manage. 218, 291-299, 2018.

[29] V. Ayan, M.C. Limbachiya, J.R. Omer, S. Masoud, N. Azadani, Compaction assessment of recycled aggregates for use in unbound subbase application, J. Civ. Eng. Manag. 20, 169-174, 2014.

[30] JKR, Standard Specification for Road Works (JKR/SPJ/2008) Section 4: Flexible Pavement, 2008.

[31] S.N.A. Jeffry, R.P. Jaya, N. Abdul Hassan, H. Yaacob, M.K.I.M. Satar, Mechanical performance of asphalt mixture containing nano-charcoal coconut shell ash, Constr. Build. Mater. 173, 40-48, 2018.

[32] D.X. Xuan, L.J.M. Houben, A.A.A. Molenaar, Z.H. Shui, Mechanical properties of cement-treated aggregate material - A review, Mater. Des. 33, 496-502, 2012.

[33] N.N.M. Pauzi, M. Jamil, R. Hamid, A.Z. Abdin, M.F.M Zain, Influence of spherical and crushed waste Cathode-Ray Tube (CRT) glass on lead $(\mathrm{Pb})$ leaching and mechanical properties of concrete. J Build Eng. 21, 421-428, 2019. 